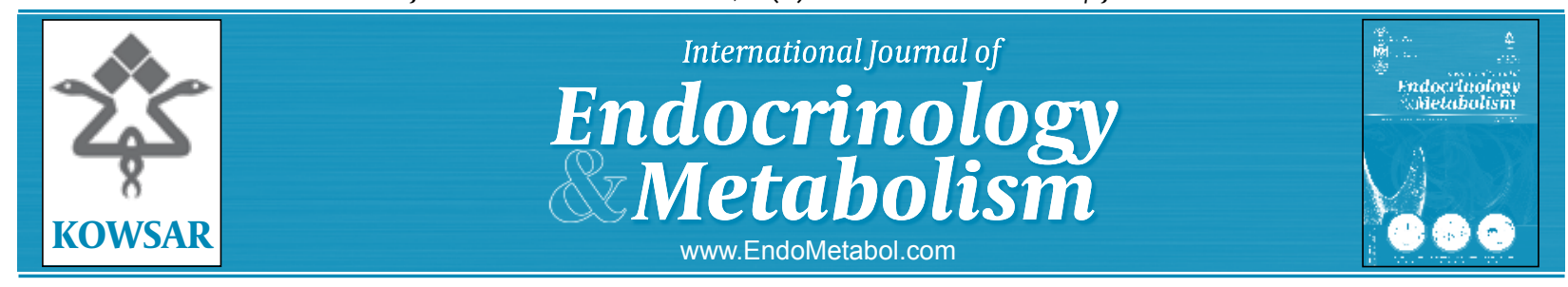

\title{
Prevalence and Risk Factors for Non-Vertebral Fractures in Patients Receiving Oral Glucocorticoids
}

\section{Sosa-HenrIquez Manuel ${ }^{1,2^{*}}$, Gomez de Tejada-Romero Maria Jesus ${ }^{1}$, Saavedra-Santana Pedro ${ }^{2}$, Blazquez-Cabrera Jose Antonio ${ }^{3}$, Garcia-Vadillo Jesús Alberto ${ }^{4}$, Valdes-Llorca Carmen ${ }^{5}$, Diaz- Curiel Manuel ${ }^{6}$, Munoz-Torres Manuel ${ }^{7}$, Martinez-Rodriguez Maria Elena ${ }^{8}$, Navarro-Ceballos Carmen $^{9}$, Sanfelix-Genoves Jose ${ }^{10}$, Cancelo-Hidalgo Maria Jesus ${ }^{11}$, Carpintero-Benitez Pedro ${ }^{12}$, Mesa-Ramos Manuel ${ }^{13}$,Palacios-Gil Antunano Santiago ${ }^{14}$ and Spanish and International Scien- tific Societies of the SEIOMM study of Glucocorticoids Osteoporosis ${ }^{\Delta}$}

\footnotetext{
${ }^{1}$ Spanish Society for Investigation of Osteoporosis and Bone Metabolic Diseases (SEIOMM), Madrid, Spain

${ }^{2}$ University of Las Palmas de Gran Canaria, Madrid, Spain

${ }^{3}$ Spanish Society of Internal Medicine (SEMI), Madrid, Spain

${ }^{4}$ Spanish Society of Rheumatology (SER), Madrid, Spain

${ }^{5}$ Spanish Society of General Practitioners (SEMERGEN), Madrid, Spain

${ }^{6}$ Spanish Foundation for Osteoporosis and Metabolic Diseases (FHOEMO), Madrid, Spain

${ }^{7}$ Spanish Society of Endocrinology and Metabolism (SEEN), Madrid, Spain

${ }^{8}$ Spanish Society of Physical Medicine and Rehabilitation (SERMEF), Madrid, Spain

${ }^{9}$ Spanish Society of Geriatrics and Gerontology (SEGG), Madrid, Spain

${ }^{10}$ Spanish Society of General Practitioners (SEMFyC), Madrid, Spain

${ }^{11}$ Spanish Association for Study of Menopause (AEEM), Madrid, Spain

${ }^{12}$ Spanish Society for Study of Osteoporotic Fractures (SEFRAOS), Madrid, Spain

${ }^{13}$ Spanish Society of Orthopaedic Surgeons (SECOT), Madrid, Spain

${ }^{14}$ International Society of Osteoporosis and Bone Mineral Metabolism (SIBOMM), Madrid, Spain
}

\begin{tabular}{|c|c|}
\hline A R T I C L E I N F O & A B S T R A C T \\
\hline Article type: & \multirow{12}{*}{$\begin{array}{l}\text { Introduction: Glucocorticoids taken orally increase the risk of fractures. It has been noted } \\
\text { that a dose as low as } 2.5 \mathrm{mg} / \text { day increases the risk of vertebral fracture. What is less clear is } \\
\text { the possible influence of other risk factors for osteoporosis on the presence of non-vertebral } \\
\text { fractures in patients taking glucocorticoids. } \\
\text { Patients and Methods: A cross-sectional study, performed on } 513 \text { men and women from } \\
\text { Spain, who were taking at least } 7.5 \mathrm{mg} / \text { day of oral prednisone for a minimum of } 3 \text { months. } \\
\text { A questionnaire was developed, through which information on risk factors was collected. } \\
\text { Results: } 28.3 \% \text { of the patients who were taking glucocorticoids at a daily oral dose of } 7.5 \mathrm{mg} / \\
\text { day for a minimum of } 3 \text { months had suffered at least one non-vertebral fracture. The risk } \\
\text { increased with age, the number of months the glucocorticoids had been taken, the presence } \\
\text { of falls in the last year and, above all, with a maternal history of hip fracture. } \\
\text { Conclusions: In patients taking oral glucocorticoids for over } 3 \text { months at doses higher than } \\
7.5 \text { mg/day of prednisone or equivalent, the prevalence of non-vertebral fractures was } 28.3 \% \text {. } \\
\text { Some risk factors associated with the presence of these fractures were identified. The dura- } \\
\text { tion of glucocorticoid use appears to be more strongly related to the presence of non-verte- } \\
\text { bral fractures than the daily dose. }\end{array}$} \\
\hline Original Article & \\
\hline Article history: & \\
\hline Received: 07 Nov 2011 & \\
\hline Revised: 17 Feb 2012 & \\
\hline Accepted: 02 Mar 2012 & \\
\hline Keywords: & \\
\hline Adrenal Cortex Hormones & \\
\hline Osteoporosis & \\
\hline & \\
\hline & \\
\hline & \\
\hline
\end{tabular}

* Corresponding author: Manuel Sosa, Espronceda No. 2. 35005, Las Palmas de Gran Canaria, Canary Islands, Spain. Tel: +34-928451456, Fax: +34Copyright @ 2012 Kowsar Corp. All rights reserved. 928451428,E-mail:msosa@ono.com

${ }^{\Delta}$ Compelte name and affilation of Spanish and International Scientific Societies of the SEIOMM study are listed at the end of this article as an Appendix (page:483).

DOI:10.5812/ijem.3442

Copyright @2012 Kowsar Corp. All rights reserved. 
Implication for health policy/practice/research/medical education:

This study focus on the Some risk factors associated with the presence of non-vertebral fractures in patients taking glucocorticoids.

- Please cite this paper as:

Sosa M, Gomez-de-Tejada MJ, Saavedra P, Blazquez JA, Garcia JA, Valdes C, et al. Prevalence and Risk Factors for Non-Vertebral Fractures in Patients Receiving Oral Glucocorticoids . Int J Endocrinol Metab. 2012;10(2):480-485. DOI: 10.5812/ijem.3442

\section{Introduction}

The detrimental effect that glucocorticoids taken orally have on bone mineral metabolism is well known (1-4). Loss of bone mineral density (BMD) (detected both by dual X-ray absorptiometry [DXA] and ultrasound [QUS]), deterioration in bone quality and increased prevalence of vertebral, non-vertebral and hip fractures have been reported. Van Staa et al. were able to establish the dose and period of time required to produce an increase in the risk of both vertebral and hip fractures. The relative rate of non-vertebral fracture during oral glucocorticoid treatment was 1.33 (95\% confidence interval [CI], 1.291.38), 1.61 for hip fracture (1.47-1.76), 1.09 for forearm fracture (1.01-1.17) and 2.60 for vertebral fracture (2.31-2.92). A dose-dependent risk of fracture was observed. With a standardized daily dose of less than $2.5 \mathrm{mg}$ prednisolone, the hip fracture risk was $0.99(0.82-1.20)$ relative to a control group, rising to 1.77 (1.55-2.02) at daily doses of 2.5-7.5 $\mathrm{mg}$ and 2.27 (1.94-2.66) at doses of $7.5 \mathrm{mg}$ or greater. For vertebral fracture, the relative rates were 1.55 (1.20-2.01), 2.59 (2.16-3.10) and 5.18 (4.25-6.31) (5-7).

Less is known, however, about the role of other risk factors in the pathogenesis of fragility fractures associated with glucocorticoid therapy. The aim of this study was to investigate the prevalence of non-vertebral fractures in a population of men and women on long-term glucocorticoid therapy and to examine the role of other risk factors.

\section{Patients and Methods}

This was a cross-sectional, observational, co-operative and multicenter study performed jointly by the Spanish Society for Bone and Mineral Metabolism Research (SEIOMM) and all the national scientific societies related to osteoporosis. In Appendix 1, there is a list of these societies, their national co-ordinators and the individuals who collaborated in this study.

Clinical data were collected from a total of 519 men and women from Spain. The criteria for inclusion in the study were: patients of both genders, age over 40 years and the taking of oral steroids at a minimum $7.5 \mathrm{mg} /$ daily of prednisone or equivalent over a period of 3 consecutive months or more. Of these patients, 6 were excluded because they did not meet the inclusion criteria. Patients were recruited through the participating centers over a 10-week period. The clinicians selected the patients as they attended the medical practices. In the end, 513 individuals were included.
A questionnaire was developed that collected information about the distribution of some risk factors related to osteoporosis, which included all those in $\operatorname{FRAX}^{\circledR}(8,9)$. Prevalence of tobacco and alcohol consumption during the last month (yes or no) was used to properly classify the participants. Fractures were recorded from written reports from radiologists, emergency reports, and X-rays provided by the patients and after examining their medical records. In both patients and controls, fractures were recorded only if properly documented and occurring with a minor trauma, as long as a record existed for each patient, with the exception of childhood fractures, which were excluded.

\subsection{Statistical Analysis}

The clinical data were entered into a database through the SEIOMM web page, and were subsequently exported to the SPSS program, which was used to carry out the following statistical analysis.

In each of the study groups, the categorical variables are summarized in frequencies and percentages, and the numerical variables are presented in averages and standard deviations (SD), or medians and interquartile ranges (IQR), according to whether assumed normality was indicated or not. The percentages were compared using the chi-squared test, the averages with the t-test and the medians with the Wilcoxon test for independent data. The variables that showed statistical significance in the univariate analysis were entered into a multidimensional logistic analysis. In the first stage, a retrospective selection was made based on the Akaike criteria (AIC). Subsequently, the variables entered into the model were explored using additive logistic models. The final models were summarized in p-values, odd-ratios for linear effects and graphical representations for non-linear effects. In both cases, 95\% confidence intervals were obtained. An effect was considered to be statistically significant when the corresponding $P$ value was lower than 0.05. The analysis was carried out using the R program.

Written consent to participate in the study was requested from all patients. The study was approved by the Committee on Clinical Trials of the Maternal-Insular Hospital Complex of Gran Canaria.

\section{Results}

A total of 513 patients were included. The patients were classified into two groups, depending on the existence 
Table 1. Comparison of Baseline Characteristics of the Study Population, as a Function of the Presence or Non-Presence of Non-Vertebral Fractures.

\begin{tabular}{|c|c|c|c|}
\hline & \multicolumn{2}{|c|}{ Fractures } & \multirow[b]{2}{*}{ Pvalue } \\
\hline & Yes $(n=145)$ & No $(n=368)$ & \\
\hline Age, y & $67.5 \pm 13.4$ & $58.1 \pm 16.3$ & $P<0.001$ \\
\hline Men / Women ,\% & $23.4 / 26.4$ & $76.6 / 73.6$ & 0.496 \\
\hline Weight, kg & $65.9 \pm 14.2$ & $71.2 \pm 14.5$ & $P<0.001$ \\
\hline Height, cm & $158 \pm 8.9$ & $161 \pm 9.3$ & $P<0.001$ \\
\hline $\mathrm{BMI}^{\mathrm{a}}, \mathrm{kg} / \mathrm{m}^{2}$ & $26.5 \pm 5.5$ & $27.3 \pm 5.1$ & 0.093 \\
\hline Height/Arm span & $0.994 \pm 0.04$ & $0.999 \pm 0.04$ & 0.208 \\
\hline $\begin{array}{l}\text { Consumption of } \\
\text { alcohol, No.(\%) }\end{array}$ & $11(7.6)$ & $22(6.0)$ & 0.504 \\
\hline Smokers, No. (\%) & $20(13.8)$ & $62(16.8)$ & 0.395 \\
\hline Urban, No. (\%) & $123(84.8)$ & $318(86.4)$ & 0.642 \\
\hline $\begin{array}{l}\text { Mother with hip } \\
\text { fracture, No. (\%) }\end{array}$ & $38(27.1)$ & $33(9.3)$ & $P<0.001$ \\
\hline $\begin{array}{l}\text { Falls in the last } \\
\text { year, No. (\%) }\end{array}$ & $72(49.7)$ & $91(24.7)$ & $P<0.001$ \\
\hline $\begin{array}{l}\text { Menopause, No. } \\
\text { (\%)/ all women }\end{array}$ & $103(92.7) / 111$ & $200(73.8) / 271$ & $P<0.001$ \\
\hline
\end{tabular}

abbreviations: BMI, Body mass index

or non-existence of non-vertebral fractures at the time of the visit. Group I contained 145 patients with at least one non-vertebral fracture (28.3\%), while group II contained 368 patients with no history of fracture.

Fractures had occurred in $23.4 \%$ of the men and $26.4 \%$ of the women. Table 1 compares the clinical data between the two groups of patients, with or without non-vertebral fractures. Patients with fractures had higher age, lower body weight, and smaller height, although there was no difference in body mass index (BMI) between the fracture and non-fracture groups. No statistically significant differences were seen between patients with or without non-vertebral fractures in terms of height/arm span quotient, tobacco and alcohol consumption, living in urban or rural areas, or in the consumption of calcium. On the other hand, there was a statistically higher frequency of a maternal history of hip fracture among the patients with fractures, $(27.1 \% v s .9 .3 \%, P<0.001)$, of falls in the last year (49.7\% vs. $24.7 \%, P<0.001)$ and, in women, of the presence of menopause (92.7\% vs. $73.8 \%$ ).

In studying the variables related to glucocorticoid therapy (Table 2), both the total treatment in months (37vs.21, $P<0.001)$ and the treatment in months with the mainte- nance dose (480 vs. $240, P<0.001)$ were associated with the presence of fractures.

Multivariate logistic analysis demonstrated that the presence of non-vertebral fractures, age, maternal history of hip fracture, falls and the duration of treatment with glucocorticoids were all significant independent predictors of non-vertebral fracture (Table 1, Figure 1).

\begin{tabular}{lll}
\hline \multicolumn{3}{l}{ Table 3. Multidimensional Logistic } \\
\hline & P valusis & \\
\hline Age (for each year) & $P<0.001$ & $1.040(1.023 ; 1.057)$ \\
Maternal history of hip fracture & $P<0.001$ & $4.000(2.385 ; 6.706)$ \\
Falls in the last year & $P<0.001$ & $1.755(1.105 ; 2.789)$ \\
Months in treatment with steroid & $P<0.001$ & Non-linear effect \\
\hline
\end{tabular}

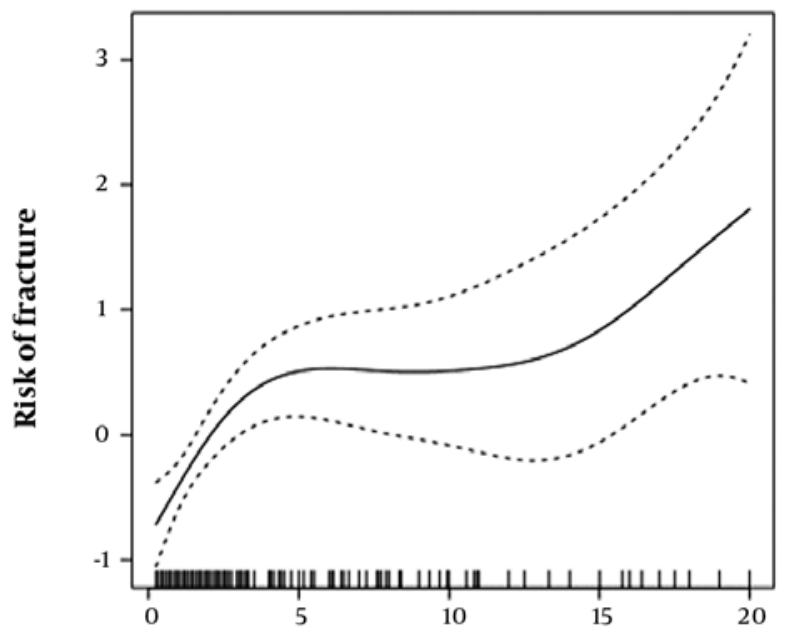

Time with steroids. (Years)

Figure 1. Effect Over Time of Taking Steroids on the Risk of Non-Vertebral Fractures

\section{Discussion}

All the patients in our study were taking long-term glucocorticoids at a dose of at least $7.5 \mathrm{mg} /$ day over 3 months. Our principal objective was to establish risk factors for the development of non-vertebral fractures. Nonvertebral fractures are common, affecting $1 \%$ of the population/year and are responsible for a large proportion of

\begin{tabular}{|c|c|c|c|}
\hline & \multicolumn{2}{|c|}{ Non-Vertebral Fractures ${ }^{a}$} & \multirow[b]{2}{*}{ P value } \\
\hline & Yes $(n=145)$ & No $(n=368)$ & \\
\hline Current dose of steroids, mg/day & $15(10 ; 20)$ & $15(10 ; 20)$ & 0.768 \\
\hline Usual dose of corticoids, mg/day & $15(10 ; 20)$ & $15(10 ; 20)$ & 0.544 \\
\hline Cumulative dose of corticoids received, $\mathrm{mg}$ & $480(240 ; 1200)$ & $240(105 ; 720)$ & $<0.001$ \\
\hline Daily dose ${ }^{\mathrm{b}}$, No. $(\%)$ & $131(91.6)$ & $350(95.1)$ & 0.131 \\
\hline Months in treatment with steroids & $39(20 ; 72)$ & $21(7 ; 58)$ & $<0.001$ \\
\hline
\end{tabular}

${ }^{\mathrm{a}}$ The values are expressed in medians (IQR) or frequencies and percentages

${ }^{\mathrm{b}}$ Daily intake of corticoids as opposed to alternate days. 
the morbidity, mortality and cost attributable to osteoporosis (10). In our study, as many as $28.3 \%$ of patients who were taking glucocorticoids had a non-vertebral fracture at the time of evaluation. Van Staa et al. reported that the risk of non-vertebral fractures in individuals taking glucocorticoids was 2.0 per 100 person-years as compared with an incidence of 1.3 in the control group (5-7). Our study was cross-sectional; therefore, we only have data on prevalence.

Table 1 shows that patients who sustained a non-vertebral fracture were older and had lower body weight and height, a higher prevalence of maternal history of hip fracture and a higher prevalence of falls than patients without fractures. Women with fractures were more likely to be menopausal than those without fractures. All of these are well known risk factors for osteoporosis (8, 9, 11-13) and have previously been described in patients receiving glucocorticoids (14-19).

Glucocorticoid dose and duration can be defined in several ways. In this study, current consumption was defined as the dose of steroids that the patient was taking at the time of the interview. The usual or maintenance dose was the dose that the patient had been taking for most of the time during their period of glucocorticoid therapy. Duration of therapy was expressed as the number of consecutive months of treatment. Van Staa et al. reported that the risk of fracture in patients using oral glucocorticoids was strongly related to the daily dose (6), but this relationship was not seen in our study. It must be taken into account that the two studies differ in design; the study conducted by Van Staa et al. was longitudinal, while our study was cross-sectional.

Table 2 shows that the duration, but not dose, of glucocorticoids was different in patients with and without fractures. Thus the overall duration of treatment and the duration of treatment with the usual dose were associated with the appearance of non-vertebral fractures. However, there was no association in relation to dosage. Thus, the current dose of glucocorticoids, maintenance dose and daily versus alternate day use showed no association with the presence of non-vertebral fractures. Studies carried out on steroidal osteoporosis in daily clinical practice present a problem that is difficult, if not impossible, to resolve, which is the variability of doses that patients receive in a specific period of time, however long that may be. Thus, two patients of the same age and sex, with the same disease and with similar anthropometric characteristics could be taking different doses of corticoids to control their disease. Therefore, over a set period of time, they may need higher or lower doses of corticoids, and this cannot be established beforehand. In addition, in certain episodic diseases, for example bronchial asthma or multiple sclerosis, patients may receive high doses of corticoids for short periods of time. Lastly, some pathologies may be controlled by administering corticoids on alternate days. For this reason, when evaluating the effect of corticoids on the bone, many authors prefer to use the accumulated dose of corticoids $(20,21)$. In our study, we have included the concept of usual dose, as explained above, but this variable was not associated in a statistically significant way with the presence or absence of non-vertebral fractures, since the patients with fractures had a habitual dose similar to both groups: 15 $\mathrm{mg} /$ day of prednisone, $p=0.544$.

When we performed a multidimensional logistic analysis to assess which variables were associated with the presence of non-vertebral fractures, the only variables selected were age, maternal history of hip fracture, the presence of falls and the time (in months) that the glucocorticoids had been taken. Figure 1 shows the relationship between the duration of use and the prevalence of non-vertebral fractures. Perhaps unexpectedly, neither the current or usual dose of steroids was associated with fracture prevalence. Maternal history of hip fracture is a well-known risk factor for osteoporosis, but its importance as a risk factor for glucocorticoid-induced osteoporosis has not been previously described in the literature.

One of the limitations of this study is that only nonvertebral fractures were recorded, since lateral spine $\mathrm{X}$ rays were not routinely performed. Nevertheless, all nonvertebral fractures were verified radiologically. In fact, since this was a cross-sectional study, it is possible that a selection bias may have occurred. Longitudinal studies are preferred because they can better assess the effect of corticoids on the risk of developing fragility fractures.

In summary, in this study who were taking glucocorticoids orally for over 3 months at doses higher than 7.5 $\mathrm{mg} /$ day had a prevalence of non-vertebral fractures of 28.3\%. Some risk factors associated with the presence of these fractures were also identified, such as greater age, lower body weight and height, higher prevalence of a maternal history of fractures and a higher prevalence of falls. The duration of glucocorticoid use was more strongly related to the presence of non-vertebral fractures than the dose.

\section{Acknowledgments}

We would like to thank Professor Juliet Compston from Cambridge, UK, for her kind comments and suggestions.

\section{Financial Disclosure}

None declared.

\section{Funding/Support}

None declared.

\section{${ }^{\circ}$ Appendix 1}

Spanish and International Scientific Societies related to the study of osteoporosis that have participated in this study include the following:

Spanish Association for the Study of Menopause (AEEM). Coordinator: Maria Jesus Cancelo Hidalgo. 
Hispanic Foundation for the Study of Osteoporosis and Bone Metabolism (FHOEMO). Coordinator: Manuel Diaz Curiel.

Spanish Society of Orthopaedic Surgery and Traumatology (SECOT-GEIOS). Coordinator: Manuel Mesa Ramos.

Spanish Society of Endocrinology and Nutrition (SEEN).

Coordinator: Manuel Muñoz Torres.

Spanish Society of Osteoporotic Fractures (SEFRAOS). Coordinator: Pedro Carpintero.

Spanish Society of Geriatrics and Gerontology (SEGG).

Coordinator: Carmen Navarro Ceballos.

Spanish Society of Family and Community Medicine (SEMFyC). Coordinator: Jose Sanfelix Genoves.

Spanish Society of General Medicine (SEMERGEN). Coordinator: Carmen Valdes y Llorca.

Spanish Society of Internal Medicine (SEMI). Coordinator: Jose Antonio Blazquez Cabrera.

Spanish Society of Physical Medicine and Rehabilitation (SERMEF). Coordinator: Maria Elena Martinez Rodriguez.

Spanish Society of Rheumatology (SER). Coordinator: Alberto Garcia Vadillo.

Iberoamerican Society of Osteoporosis and Mineral Metabolism (SIBOMM). Coordinator: Santiago Palacios Gil-Atunano

\section{Appendix 2.}

AEEM: Jose Luis Neyro Bilbao.

FHOEMO: Maria Jesus Moro Alvarez; Antonio Torrijos Eslava.

SECOT-GEIOS: Xurso Novoa.

SEEN: Esteban Jodar Gimeno; Ines Luque Fernandez; Guillermo Martinez Diaz Guerra; Jose Manuel Quesada Gomez, Pedro Rozas Moreno.

SEGG:Alvaro Casas Herrero; Francesc Formiga; Teresa Gonzalez; Maria Gonzalo; Montserrat Lazaro; Pilar Mesa Lampre.

SEIOMM: Josep Blanch Rubio; Javier del Pino Montes; Leonardo Mellivobsky Saidler; Pilar Orozco Lopez; Lucia Silva; Daniel Roig Vilaseca.

SEMERGEN: Salvador Alvarez; Milagros Gonzalez Bejar; Maria Jose Jimeno.

SEMFyC: Silvia Dorado Rabaneda; Vicente Giner Ruiz; Fernando Leen Vazquez; Inmaculada Pereiro Berenguer; Alvaro Perez Martin; Nidia Ruiz Varela; Alejandro Tejedor Varilla; Francisco Vargas Negrin.

SEMI: Rosa Bautista Salinas; Luz Marina Calvo Hernandez; Begona de Escalante Yangüe; Jose Filgueira Rubio; Maria Angeles Galindo Andugar; Rocio Gonzalez Leon; Jose Luis Hernandez Hernandez; Diego Hernandez Hernandez; Jose Andres Lopez-Herce Cid; Maria del Val Martin Sanz; Elena Molina Pacheco; Amalia Navarro Martinez; Xavier Nogues i Solan; Norberto Ortego Centeno; Jose Luis Perez Castrillon; Blanca Pinilla; Pilar Sanchez Molini; Mercedes Suarez Cabrera; Raimundo Tirado Miranda; Maria Angeles Vazquez Gamez.

SER: Marcelo Calabozo Raluy; Luis Espadaler; Pilar Es- pino; Julia Fernandez Melon; Jordi Fiter Ariste; Elena Garmendia Sanchez ; Maria Teresa Gonzalez Hernandez; Jose Gonzalez Dominguez; Javier Gonzalez Polo; Sara Manrique; Irigoyen Oyarzabal; Enrique Raya Alvarez; Monica Vazquez Diaz.

SERMEF: Mirian Gutierrez Retortillo; Soraya Hijazi Vega; Francisco Luna Cabrera; Xoan Miguens Vazquez; Juan Antonio Olmo Fernandez; Andres Pena Arrebola; Maria Cristina Tena-Davila Mata.

SEFRAOS: Adolfo Diez-Perez.

\section{References}

1. Tatsuno I, Sugiyama T, Suzuki S, Yoshida T, Tanaka T, Sueishi M, et al. Age dependence of early symptomatic vertebral fracture with high-dose glucocorticoid treatment for collagen vascular diseases. J Clin Endocrinol Metab. 2009;94(5):1671-7.

2. Thompson JM, Modin GW, Arnaud CD, Lane NE. Not all postmenopausal women on chronic steroid and estrogen treatment are osteoporotic: predictors of bone mineral density. Calcif Tissue Int.1997;61(5):377-81.

3. Vestergaard P, Rejnmark L, Mosekilde L. Fracture risk associated with systemic and topical corticosteroids. J Intern Med. 2005;257(4):374-84

4. Walsh LJ, Lewis SA, Wong CA, Cooper S, Oborne J, Cawte SA, et al. The impact of oral corticosteroid use on bone mineral density and vertebral fracture. Am J Respir Crit Care Med.2002;166(5):691-5.

5. van Staa TP, Leufkens HG, Abenhaim L, Zhang B, Cooper C. Oral corticosteroids and fracture risk: relationship to daily and cumulative doses. Rheumatology (Oxford). 2000;39(12):1383-9.

6. Van Staa TP, Leufkens HG, Abenhaim L, Zhang B, Cooper C. Use of oral corticosteroids and risk of fractures. J Bone Miner Res. 2000;15(6):993-1000.

7. van Staa TP, Leufkens HG, Cooper C. The epidemiology of corticosteroid-induced osteoporosis: a meta-analysis. Osteoporos Int. 2002;13(10):777-87.

8. Kanis JA, Johnell O, Oden A, Johansson H, McCloskey E. FRAX and the assessment of fracture probability in men and women from the UK. Osteoporos Int. 2008;19(4):385-97.

9. Kanis JA, Oden A, Johansson H, Borgstrom F, Strom O, McCloskey E. FRAX and its applications to clinical practice. Bone. 2009;44(5):734-43.

10. Roux C, Briot K, Horlait S, Varbanov A, Watts NB, Boonen S. Assessment of non-vertebral fracture risk in postmenopausal women. Ann Rheum Dis. 2007;66(7):931-5.

11. Kaptoge S, Reid DM, Scheidt-Nave C, Poor G, Pols HA, Khaw KT, et al. Geographic and other determinants of BMD change in European men and women at the hip and spine. a populationbased study from the Network in Europe for Male Osteoporosis (NEMO). Bone. 2007;40(3):662-73.

12. Leslie WD, Anderson WA, Metge CJ, Manness LJ. Clinical risk factors for fracture in postmenopausal Canadian women: a population-based prevalence study. Bone. 2007;40(4):991-6.

13. Reginster JY, Burlet N. Osteoporosis: a still increasing prevalence. Bone. 2006;38(2 Suppl 1):S4-9.

14. Angeli A, Guglielmi G, Dovio A, Capelli G, de Feo D, Giannini S, et al. High prevalence of asymptomatic vertebral fractures in postmenopausal women receiving chronic glucocorticoid therapy: a cross-sectional outpatient study. Bone. 2006;39(2):253-9.

15. Weinstein RS. Glucocorticoids, osteocytes, and skeletal fragility: the role of bone vascularity. Bone.46(3):564-70.

16. Caplan L, Saag KG. Glucocorticoids and the risk of osteoporosis. Expert Opin Drug Saf. 2009;8(1):33-47.

17. De Nijs RN. Glucocorticoid-induced osteoporosis: a review on pathophysiology and treatment options. Minerva Med. 2008;99(1):23-43.

18. den Uyl D, Bultink IE, Lems WF. Advances in Glucocorticoid-Induced Osteoporosis. Curr Rheumatol Rep. 2011;13(3):233-40.

19. Maricic M. Glucocorticoid-induced osteoporosis: treatment op- 
tions and guidelines. Curr Osteoporos Rep. 2005;3(1):25-9.

20. Reid IR, Heap SW. Determinants of vertebral mineral density in patients receiving long-term glucocorticoid therapy. Arch Intern
Med.1990;150(12):2545-8.

21. Reid IR. Steroid-induced osteoporosis. Osteoporos Int. 1997;7(Suppl 3):S213-6. 